\title{
Nathalie Caron, Guillaume Marche (dir.), La politisation du religieux en modernité
}

Rennes, Presses universitaires de Rennes, coll. " Sciences des religions ", 2015, 200 p., postface de Jean-Paul Willaime

Jacques Palard

\section{CpenEdition}

Journals

Édition électronique

URL : http://journals.openedition.org/assr/28204

DOI : $10.4000 /$ assr.28204

ISSN : $1777-5825$

Éditeur

Éditions de l'EHESS

Édition imprimée

Date de publication : 31 décembre 2016

Pagination : 284

ISSN : 0335-5985

Référence électronique

Jacques Palard, « Nathalie Caron, Guillaume Marche (dir.), La politisation du religieux en modernité », Archives de sciences sociales des religions [En ligne], 176 | octobre-décembre 2016, mis en ligne le 17 juillet 2017, consulté le 24 septembre 2020. URL : http://journals.openedition.org/assr/28204 ; DOI : https://doi.org/10.4000/assr.28204

Ce document a été généré automatiquement le 24 septembre 2020.

(c) Archives de sciences sociales des religions 


\section{Nathalie Caron, Guillaume Marche (dir.), La politisation du religieux en modernité}

Rennes, Presses universitaires de Rennes, coll. « Sciences des religions », 2015, 200 p., postface de Jean-Paul Willaime

\section{Jacques Palard}

\section{RÉFÉRENCE}

Nathalie Caron, Guillaume Marche (dir.), La politisation du religieux en modernité, Rennes, Presses universitaires de Rennes, coll. « Sciences des religions », 2015, 200 p., postface de Jean-Paul Willaime

1 C'est à une réévaluation du processus de sécularisation qu'invitent les auteurs de cet ouvrage. L'introduction défend le point de vue selon lequel la modernité a produit non pas la fin de la religion, mais un nouveau régime et de nouvelles conditions de croyances. Elle souligne que les études de cas - tous anglo-saxons - qui sont présentées conduisent à considérer les liens entre le religieux et le politique non sous l'angle d'une rupture, mais sous celui d'une complexification, voire d'un resserrement. Le recours à la notion de «transfert » traduit ainsi un processus de relative dédifférenciation et une porosité des frontières qui n'exclut toutefois pas une nette asymétrie puisque, «si le politique sécularisé peut se passer du religieux, le religieux, lui, ne peut renoncer au politique» (p.13). C'est cette asymétrie qui fonde l'une des originalités de l'ouvrage revendiquées par ses auteurs, qui entendent privilégier l'attention accordée de façon délibérée au mouvement qui va du religieux au politique. Dans sa postface, J.-P. Willaime inscrit d'emblée le sacré à l'entrecroisement de ces deux champs institutionnels.

L'ouvrage est découpé en trois parties : " Discours ", « Organisation », "Actions », dont l'ensemble des onze chapitres couvrent quatre pays : l’Angleterre, la Nouvelle-Zélande, 
la République d'Irlande et les États-Unis. On peut estimer que ses initiateurs n'accordent pas une place suffisante à l'explicitation de ce choix et, surtout, à l'élucidation de la possible illusion d'optique qui tient au traitement d'époques que séparent plusieurs siècles. Des contributions portent sur la période actuelle, celles en particulier qui sont consacrées à l'Église catholique de la République d'Irlande, à l'offensive évangélique en Nouvelle-Zélande ou à l'engagement de la gauche religieuse dans la réforme du système de santé aux États-Unis; d'autres, au contraire, transportent le lecteur au $\mathrm{XVI}^{\mathrm{e}}$ siècle, pour y observer l'approche liturgique de la suprématie royale sous le règne d'Henri VIII, ou au XVII ${ }^{\mathrm{e}}$ siècle, pour $\mathrm{y}$ analyser, toujours en Angleterre, le mythe de l'anticatholicisme ou le discours religieux de Thomas de Quincey. À cet égard, le titre de l'ouvrage peut porter à confusion, sauf bien sûr à considérer qu'il y a plusieurs modernités successives, mais cette position mériterait à son tour d'être expliquée et défendue.

3 La pluralité des études consacrées à la même période pour un même pays offre au lecteur la possibilité de croiser les informations ainsi traitées. Le XVII siècle anglais bénéficie ainsi d'un double regard sur d'importantes innovations qui témoignent de l'influence du discours politique sur les orientations religieuses. Gaby Mahlberg estime innover en attirant l'attention sur l'ouverture et la relative bienveillance des républicains à l'égard des catholiques, attitude qui est commandée par des raisons tout à la fois politiques et doctrinales; les républicains ont fortement contribué à la lutte des catholiques pour la liberté de conscience. Cyril Selzner, qui inscrit sa contribution dans ce qu'il dénomme précisément une "première modernité » (p. 32), s'attache à analyser les prolongements de la notion de conscience sur le plan théologico-politique au cours des années 1640-1660: la politisation des catégories religieuses rend pensable et donc possible la militarisation du discours religieux, dont notamment celui de Cromwell. La conscience et la foi, qui se trouvent animées d'une forme de révélation intérieure - sorte de «bible alternative» (p.38) -, sont ainsi des opérateurs de radicalisation. Deux siècles et demi plus tard, à l'encontre de la branche principale de sa confession religieuse, le méthodiste Hugh Price Hughes, défenseur de la tolérance religieuse et politique, prône un engagement dans les affaires publiques, au nom d'une théologie de l'Incarnation et d'une conception de la foi chrétienne qui prêche l'égalité et la démocratie.

Deux contributions consacrées aux États-Unis mettent également en évidence des configurations singulières. Nina J. Crimm et Laurence H. Winer montrent les effets indirects qui découlent d'une disposition législative à caractère fiscal sur l'application du Premier amendement à la Constitution, conçu par James Madison en vue de garantir notamment le libre exercice de la religion et le non-établissement d'une religion d'État. Cette disposition a été introduite en 1954 à l'initiative du futur président Lyndon B. Jonhson, alors sénateur du Texas, dans une conjoncture politique et en vue d'objectifs très circonscrits, pour interdire, à l'occasion de campagnes électorales, les interventions des organisations à but non lucratif bénéficiant de l'exemption de l'impôt fédéral ; sa conséquence majeure est d'obliger les dirigeants d'organisations religieuses et leurs fidèles de sacrifier alors leurs droits émanant du Premier amendement en matière de liberté d'expression. Sur un tout autre plan, celui de la défense par la gauche religieuse du projet de réforme du système de santé de Barack Obama, Amandine Barb analyse une telle mobilisation en termes de politisation du sacré. Prenant le contrepied de l'approche qu'elle considère comme « habituelle» (p. 160), 
elle entend ainsi appréhender dans quelle mesure le sacré se trouve bouleversé et transformé par des événements profanes (l'auteur parle à deux reprises de "profanation du sacré », p. 160 et 165), événements qui, plus largement, contribuent ainsi à la dynamique et à l'évolution interne du religieux.

En matière d'interprétation des rapports entre le religieux et le politique, l'expression " circulation mimétique », proposée par C. Selzner, pourrait sans nul doute s'appliquer aussi à l'analyse, proposée par Aude de Mézerac-Zanetti, de la reconnaissance de la suprématie royale dans la liturgie à la suite du schisme anglican, au cours du règne d'Henri VIII. Le caractère interrogatif du titre de cette contribution paraît marquer une telle hésitation : "Sacralisation ou politisation?». À l'évidence, le rituel, codifié par une nouvelle administration politico-religieuse, est ici instrumentalisé afin de faire de la suprématie royale un substitut fonctionnel de la suprématie papale et donc un dogme implicite. On dispose là d'un bon exemple des relations subtiles et complexes qui s'établissent entre régulation politique $\mathrm{du}$ religieux et régulation religieuse du politique.

6 Le caractère composite et éclectique de l'ouvrage et son ordonnancement quelque peu déséquilibré (les quatre chapitres de la première partie, consacrée aux "Discours", sont tous consacrés à la seule Angleterre d'avant le $\mathrm{xx}^{\mathrm{e}}$ siècle), ne nuisent pas en définitive à l'objectif visé par les auteurs. Il offre des illustrations intéressantes et le plus souvent originales de formes de politisation du religieux et de ses résultantes croyantes, militantes et/ou institutionnelles.

7 L'affirmation des directeurs de l'ouvrage selon laquelle «le religieux participe à sa propre sécularisation en se désacralisant » (p.12) trouve des développements dans la postface: "Sacré, politique et religion». J.-P. Willaime invite à voir dans la radicalisation de la sécularisation l'un des produits de l'ultramodernité, qui atteint non seulement le religieux, mais l'ensemble des secteurs d'activité et de légitimation à commencer par le politique, soumis en effet au même processus de désenchantement et de désacralisation. 